\title{
Research on Energy-saving Performance of Low-energy Consumption Green Buildings
}

\author{
Wenhong $\mathrm{Yu}^{1,}$, , Shengshi Tang ${ }^{1}$ and Kuan Wang ${ }^{2}$ \\ ${ }^{1}$ North China University of Technology, 100144, Beijing, China \\ ${ }^{2}$ China Railway Construction Group CO., LTD, Beijing 100131, China
}

\begin{abstract}
In view of the shortcomings of the current green building evaluation system, this paper present a new evaluating index for the energy saving performance of low-energy green buildings: CEC, and this paper evaluated and analyzed the energy-saving performance of green building by using CEC index.
\end{abstract}

\section{Introduction}

A new edition of the Green Building Evaluation Standard (GB/T 50318-2019) has been issued recently by the Ministry of Construction in China, which marks the beginning of the implementation of a new technical route for the evaluation of green buildings in China. However, in the current evaluation system of energy saving performance of green buildings, there is still a lack of measures that can take into account the whole life cycle carbon emissions of a green building and the investment increment of green technology measures. As a result, some green building technologies have larger initial investment, worse energy-saving effect and lower input-output ratio defect in the existing evaluation system.

Aiming at the above problems, this paper will give a new index to evaluate the energy saving performance of green buildings: coefficient of product of unit carbon emissions reduction unit cost (CEC). This index can provide reference for investment, design, construction, operation and evaluation of green buildings.

This paper analyzed the three-storey building (building area $7597 \mathrm{~m} 2$ ) with the above method, and the results are very good.

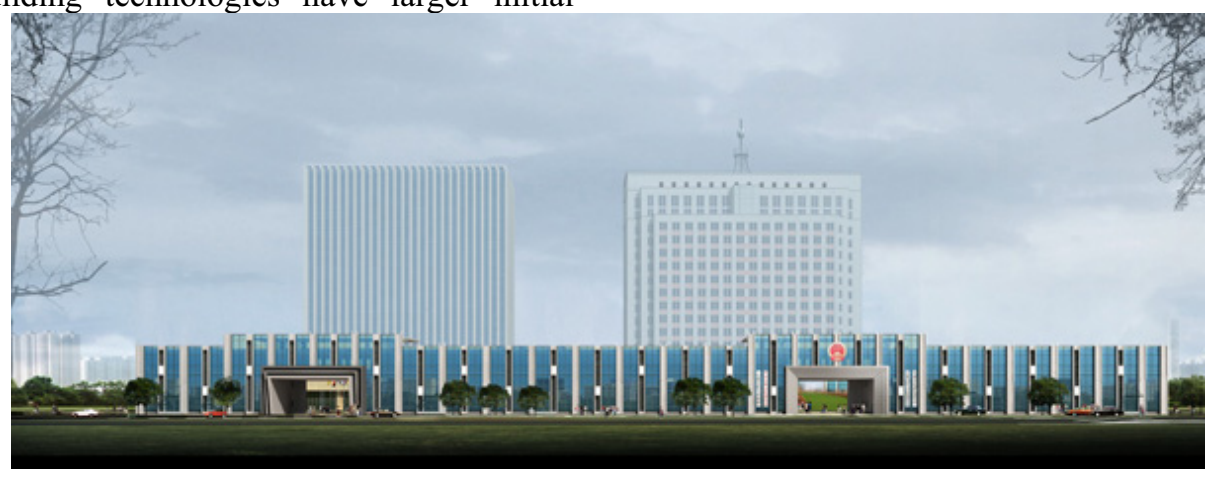

Figure 1. Effect picture of 3-storey building

\section{New Performance Evaluation for Energy-saving of Green Building}

Considering the interests of all parts and according to the original goal is to meet the challenge of global climate change, the fundamental goal of green building construction should be to use as little resources as possible to achieve the lowest possible energy consumption and carbon emissions.

Therefore, this paper puts forward the CEC index. The definition of this index is as follows:

$$
C E C=\frac{\sum_{i=1}^{k} C E_{i} * \sum_{i=1}^{k} C_{i}}{\sum_{j=1}^{k} S_{j}} * E_{C} * E_{p}
$$

The unit of $\mathrm{CEC}$ is $\mathrm{t} \cdot \mathrm{CNY} / \mathrm{m} 2$ units: $\mathrm{CEi}$ carbon emissions for phase $\mathrm{i}$ of green building projects in tonnes (t); $\mathrm{Sj}$ for building areas in different parts of the building (with different systems available) in $\mathrm{m} 2$. The $\mathrm{Ci}$ is the present money cost of the i stage, in yuan (CNY); Ec is the local supplier experience coefficient, no unit; Ep is the local expert experience coefficient, no unit.

Calculations of relevant parameters are carried out with reference to the Standard for Calculating Green

\footnotetext{
a yuwenhong@ncut.edu.cn
} 
Properties of Civil Buildings (JGJ/T449-2018) in China. The CEC index can effectively reflect the cost and carbon emission of the green technology scheme. In this article, the technical scheme with small CEC index value has more advantages.

\section{Evaluation of Energy Saving Performance of a Green Building}

This paper analyzed the three-storey building (building area $7597 \mathrm{~m} 2$ ) with the CEC index, and the results are very good. The architectural effect is shown in figure 1.

\subsection{Technical measures for energy conservation in the green buildings}

By using the CEC index, many low energy consumption green building technologies are adopted in the three-story building.

(1) Building design: various of enclosure structure schemes including Low-e glass curtain wall are calculated respectively according to the CEC index, and the energy saving implementation scheme of enclosure structure is finally determined. In the implementation scheme, some rooms have $900 \mathrm{~mm}$ high windowsill in the glass curtain wall, which effectively controls the window-wall ratio. The composite wall with external insulation is adopted.

(2) $300 \mathrm{~mm}$ thick light planting soil layers have been set up on the roof for roof greening. Light planting soil layer has heat insulation effect, and its surface vegetation has evaporative cooling effect in summer. Roof greening effectively reduces the roof cool load in summer and heat load in winter, and then reduces the energy consumption of building cooling and heating.

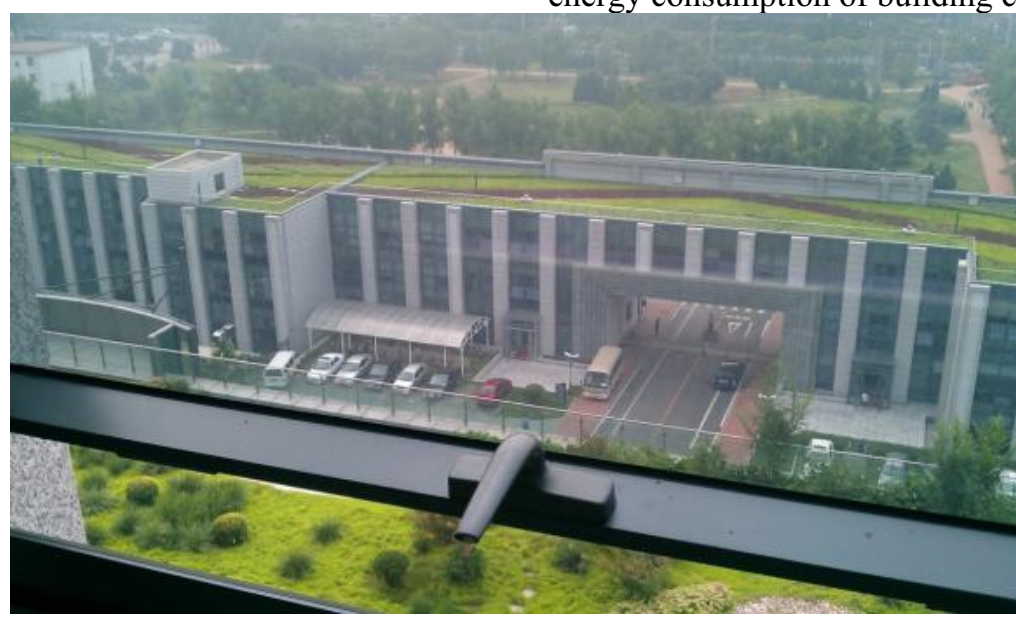

Figure 2. Roof greening of the building

(3) CEC index value is used as an important index to select the scheme of central air-conditioning system and split air conditioner in the building. Finally, the low cost, low energy consumption, low carbon emission and flexible split air conditioning system are selected and used.

(4) At the selection of building materials side, based on the CEC index, the materials or equipment with good durability are selected and used with the whole life cycle point of view in the building.

\subsection{Actual energy consumption}

In this paper, the building has been built in 2009. It has been put into use for many years, the actual energy consumption statistics are shown in figure 3, figure 4 .

As shown in figures 3 and 4 , the proportion of heating and cooling energy consumption in the building is obviously higher than that of lighting and office equipment, accounting for about $80 \%$ in winter, about $60 \%$ in summer, and $57.3 \%$ in the whole year. It can be seen that in the buildings, heating and cooling energy consumption is the main energy consumption of buildings. When evaluating the energy saving performance of green buildings, heating and cooling system should be the main evaluation object. 


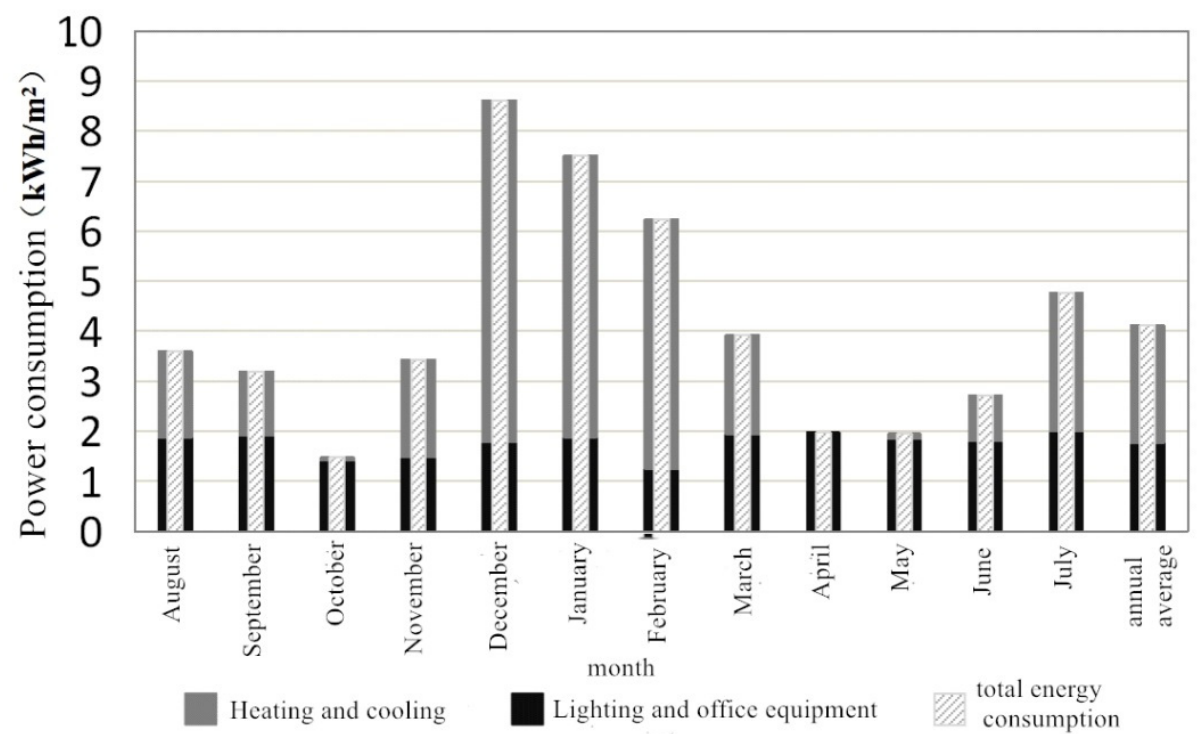

Figure 3. Annual monthly energy consumption of the Building

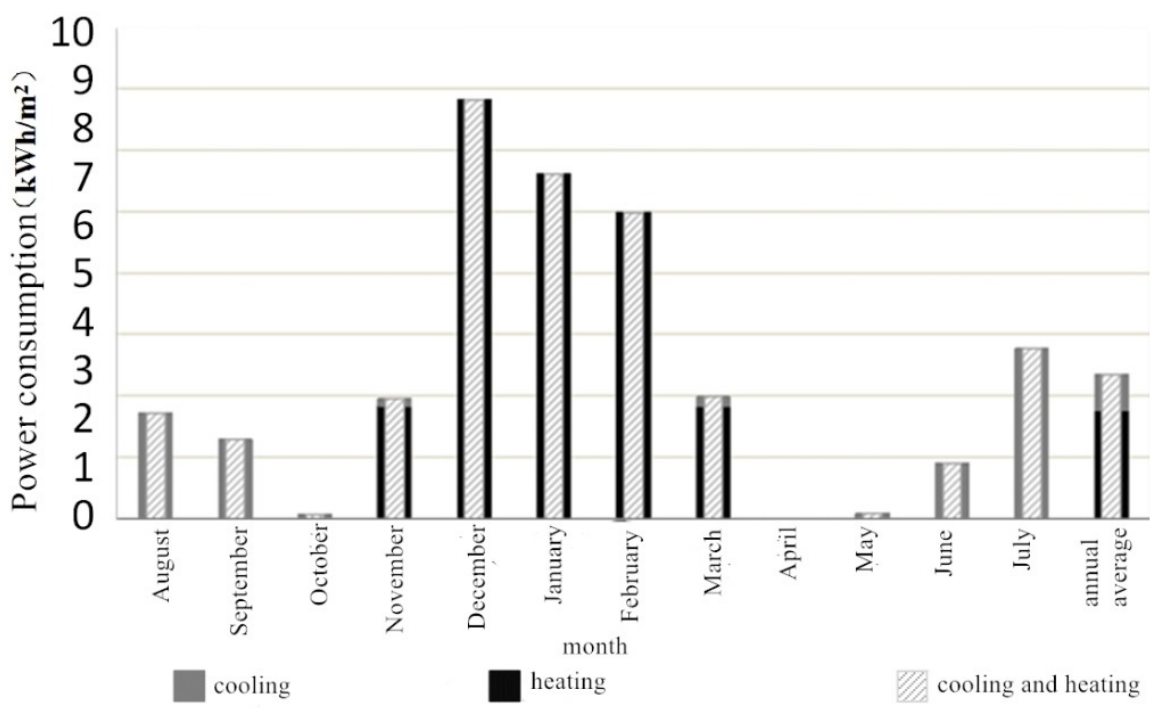

Figure 4. Annual monthly heating and cooling energy consumption of the Building

Furthermore, the total annual energy consumption per unit area of the building is $51.37 \mathrm{kWh} / \mathrm{m} 2$. Among them, the energy consumption per unit area of the cooling and heating system is $30.25 \mathrm{kWh} / \mathrm{m} 2$, only $7.08 \mathrm{kWh} / \mathrm{m} 2$ for cooling. Besides heating energy consumption, the above indexes are lower than the German PHI ultra-low energy consumption passive housing standard, and the refrigeration energy consumption is close to the near zero energy consumption demonstration building of the Institute of Science and Technology.

After obtaining the actual energy consumption data, the corresponding carbon emissions can be calculated according to the carbon emission factors of the power grid in North China, and the carbon emission factors should be $0.997(\mathrm{kgCO} 2 / \mathrm{kWh})$. The carbon emission factors can be calculated.

\subsection{CEC of the building analysis}

Figure 5 and 6 show the CEC values of the split air conditioner and the central air-conditioning system. The unit area building cost (C) and the whole life cycle carbon emission (CE) of the central air conditioning scheme of the building are significantly higher than those of the split air conditioner scheme, and the CEC value of the central air conditioning scheme is 5.54 times that of the split air conditioner scheme. From the CEC value, the central air conditioning scheme is worse to the split air conditioner scheme. 


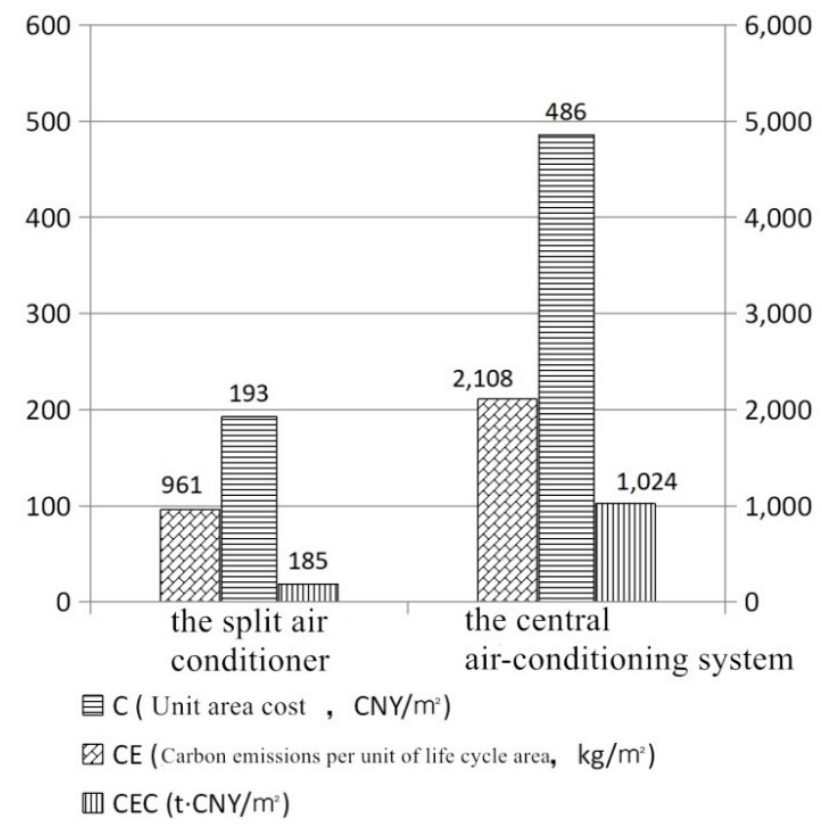

Figure 5. CEC of the split air conditioner and the central air-conditioning system

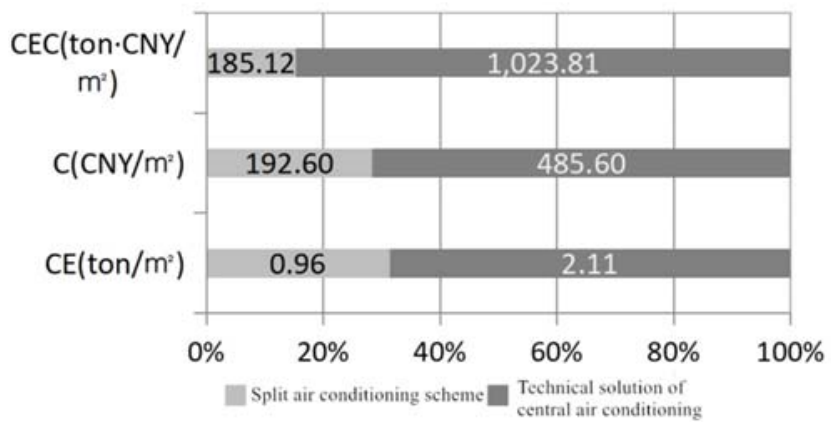

Figure 6. Comparison of $\mathrm{CEC}$ of the split air conditioner and the central air-conditioning system

\section{Conclusion}

(1) In office building, the energy consumption of heating and cooling is the main energy consumption of buildings when doing green building evaluation.

(2) CEC which proposed in this paper is essentially a quantitative index to reflect the input-output ratio of green building technical measures in energy saving and carbon emission reduction. Based on this index, it can effectively evaluate the energy saving performance of green buildings and provide reference for the investment, design, construction, operation and evaluation of green buildings.

(3) The using of CEC index shows that the split air conditioner scheme is far superior to the central air conditioning scheme in terms of energy saving and carbon emission reduction according to input-output ratio. The split air conditioner or VRV air-conditioning system should be adopted in the emphasis on investment control and energy conservation and emission reduction buildings.

\section{References}

1. GB/T 50318-2019 Green Building Evaluation Standard $[\mathrm{S}]$

2. JGJ/T449-2018 Green Performance Standard for Civil Buildings[S]

3. DB11/687-2015 Design Standards for Energy Saving in Public Buildings [S]

4. DB11/T 975-2013. Energy-saving monitoring of chillers $[\mathrm{S}]$.

5. DB11/687-2009. Public building energy efficiency design standard[S].

6. DBJ/T 15-129-2017. Centralized air conditioning refrigeration room system energy efficiency monitoring and evaluation standard [S].

7. Song Ye Hao, Wang Jialiang, Zhu Ning. China's Local Green Architecture Passive Design Strategy [J]. Reflections Journal of Architecture ,2013(7):94-99.

8. Analysis and Material Selection in the New Standard for the Evaluation of Green Buildings in [J]. Cheng Kai, Huang Shaolong Journal of Hubei University (Natural Science Edition)41(01):94-99. 
9. Liu Tong, Hua Jia, Bai Shuangyou. Research on Current Situation and Existing Problems of CDM Project Development in China [J]. and Environmental Science and Management, v.43; No.244(03): 5-9, 2018.

10. Ma Suzhen, Sun Daming, Shao Wenxi. Green Building Technology Incremental Cost Analysis [J]. Architectural Science ,2010,26(6):91-94.

11. Kenzo Yonezawa, Fumlo Yamda, Yuko Wada, et al. Comfort air-conditioning control for building energy-saving[J]. Industrial electronics society. 26th annual conference of the IEEE, 2000:1737-1742.

12. Li Song. Brief analysis of global chiller technology development trend $[\mathrm{J}]$. Refrigeration and Air Conditioning, 2016, 16(02): 100-101.

13. Liu Gang, Zhou Xinxin, Liu Kuixing. Comparative analysis based on different COP expressions of chillers[J]. Architecture Science, 2019, 35(12): 126-130.

14. Song Yingqian, Long Weiding. Application and Design of Chilled Beam Technology in Office Buildings[J]. HVAC, 2010, 40(11): 52-55. 